\title{
ENVELHECIMENTO, TRAJETÓRIAS E HOMOSSEXUALIDADE FEMININA
}

\author{
Andrea Moraes Alves \\ Universidade Federal do Rio de Janeiro - Brasil
}

Resumo: A literatura das ciências sociais sobre o tema da homossexualidade feminina tem crescido recentemente no Brasil, mostrando o interesse despertado pelo assunto. A partir dos anos 1990, trabalhos acadêmicos discutem a homossexualidade feminina: seu significado e impacto sobre as questões de gênero, sua relação com os movimentos sociais vinculados às reivindicações sobre direitos sexuais e reprodutivos no Brasil. Grande parte desses trabalhos concentra-se sobre uma faixa etária jovem, em torno dos 20 anos de idade, e outros abordam mulheres um pouco mais velhas, entre 30 e 40 anos. No entanto, nota-se a ausência de trabalhos que discutam a homossexualidade vivida por mulheres idosas. Este artigo pretende começar a preencher essa lacuna e traz à discussão o olhar das lésbicas mais velhas e suas percepções sobre o que significa a homossexualidade feminina e o lugar que ela ocupa na trajetória de vida dessas mulheres.

Palavras-chave: gênero, homossexualidade feminina, trajetórias individuais, velhice.

\begin{abstract}
The social science's literature about female homosexuality has recently grown in Brazil, showing the awakened interest in this issue. Since the 1990's, academic works have discussed female homosexuality: its meanings and its impact on gender issues, its relationships with social movements, specially the ones concerned with sexual rights in Brazil. Great part of these works focus on a young age rate, and some of them are dedicated to middle age women. However, there aren't works concerned with old age women and lesbianity. This article starts to fill this gap and takes into account old age lesbians and their perceptions about homosexuality and its place in their life trajectories.
\end{abstract}

Keywords: female homosexuality, gender, individual trajectory, old age. 


\section{Introducão}

A literatura das ciências sociais sobre o tema da homossexualidade feminina tem crescido recentemente no Brasil, mostrando o interesse despertado pelo assunto. A partir dos anos 1990, trabalhos acadêmicos discutem a homossexualidade feminina: seu significado e impacto sobre as questões de gênero, sua relação com os movimentos sociais vinculados às reivindicações sobre direitos sexuais e reprodutivos no Brasil (Almeida, 2005; Facchini, 2008; Heilborn, 1996, 2004; Lacombe, 2006; Muniz, 1992). Grande parte desses trabalhos concentra-se sobre uma faixa etária jovem, em torno dos 20 anos de idade, e outros abordam mulheres um pouco mais velhas, entre 30 e 40 anos. No entanto, nota-se a ausência de trabalhos que discutam a homossexualidade vivida por mulheres idosas. ${ }^{1}$ Este artigo pretende começar a preencher essa lacuna e traz à discussão o olhar das lésbicas mais velhas e suas percepções sobre o que significa a homossexualidade feminina e o lugar que ela ocupa na trajetória de vida dessas mulheres.

$\mathrm{O}$ argumento central do texto é que a inscrição geracional configura um "campo de possibilidades" (Velho, 1994) para a construção de formas de ser homossexual e, no caso da homossexualidade feminina, o olhar geracional permite recuperar o lugar que a sexualidade ocupa na construção das trajetórias de vida femininas.

O material da pesquisa é composto por entrevistas baseadas no modelo de história de vida feitas com quatro mulheres: uma nascida em 1934 e as outras três entre 1943 e 1947. As entrevistas foram realizadas em 2007 na cidade do Rio de Janeiro. Naquele momento, as mulheres estavam com idades entre 60 e 73 anos. Todos os depoimentos foram colhidos nas residências das entrevistadas, em uma única vez, e contaram com um roteiro estruturado em torno de temas da vida afetivo-sexual das mulheres: iniciação sexual, flertes e namoros, relações conjugais formais e informais, separações e viuvez, experiências sexuais acompanhadas ou não por vínculos estáveis. A ideia da entrevista era estimular a informante a tecer um relato de suas histórias de

1 Simões (2004) empreendeu uma pesquisa sobre a velhice e a homossexualidade masculina, e Siqueira (2009) defendeu uma tese de doutorado sobre travestis idosas e suas trajetórias de vida. 
amor e sexo ao longo da vida, começando com os primeiros flertes e namoros, a primeira experiência sexual até as vivências afetivas e sexuais na maturidade. Neste artigo, as histórias sobre as experiências sexuais serão destacadas, como: a "primeira vez", o cenário dos encontros e a manutenção da vida sexual pelo par lésbico. Abordam-se os relatos das mulheres como roteiros afetivosexuais (Gagnon, 2004), buscando principalmente identificar nesses roteiros como as mulheres conferem significados aos encontros sexuais e afetivos que tiveram ao longo da vida.

\section{Breve descrição das entrevistadas}

As quatro mulheres entrevistadas exerceram atividades remuneradas ao longo da vida, somente uma delas ainda não se aposentou e atualmente dirige seu próprio negócio (um pequeno comércio). Entre as que já são aposentadas: uma foi gerente de recursos humanos de uma grande rede de supermercados, uma trabalhou como economista em uma empresa pública e a terceira é professora de teatro em uma escola particular e ainda exerce essa atividade. Esta última é a única que não cursou o ensino superior, as demais concluíram a graduação nas áreas de economia, comunicação social e administração. Todas são brancas. Três residem na zona sul da cidade do Rio de Janeiro e uma no centro. As quatro mulheres são proprietárias dos imóveis onde residem. Uma delas vive sozinha, uma mora com a irmã, outra com uma "namorada" e outra com seus três filhos adotivos. Todas estavam em relacionamentos afetivo-sexuais estáveis no momento da entrevista. Uma estava há dois anos num relacionamento, outra há três, outra há cinco anos e outra há um ano. Em relação às experiências conjugais ao longo da vida: uma delas nunca havia vivido com alguém até recentemente (estava então coabitando há dois anos com a namorada), uma foi casada com um homem com quem teve dois filhos e hoje é avó de dois netos (a única entre as entrevistadas que relatou experiência de gravidez e aborto); ela e o esposo se separaram após dois anos de vida marital. Hoje ela tem uma namorada, mas elas moram em casas separadas sem planos de coabitação. Uma delas perdeu sua companheira num acidente; elas ficaram juntas por 20 anos, vivendo na mesma casa e adotaram três crianças. Ela também estava namorando no momento da entrevista, mas cada uma vivia na sua própria casa. Elas tinham planos de morar juntas em breve. Outra teve 
três experiências de coabitação: a primeira experiência durou quatro anos, a segunda, sete e a terceira, 15 anos. Havia um ano que ela estava namorando, mas sem planos de viver sob o mesmo teto. Essa mulher declarou jamais ter tido relações sexuais com homens.

Também compõe material da pesquisa um conjunto de entrevistas com cinco mulheres lésbicas, com idades entre 37 e 49 anos. Quatro são brancas e uma é negra, as profissões exercidas são: funcionária pública, duas assessoras de uma ONG, uma arquiteta e uma jornalista. Três residem na zona sul da cidade, uma na zona norte e outra em município localizado na região metropolitana. Quatro estavam com relações afetivas no momento da entrevista, sendo que três delas se apresentaram como "casadas" e uma estava "solteira". Uma delas tinha filhos biológicos de um casamento heterossexual anterior. Os relatos dessas mulheres serão tratados aqui como um contraponto à experiência das mais velhas, como uma forma de ressaltar diferenças geracionais. É, sobretudo, a trajetória de vida homossexual das lésbicas idosas o que constitui a discussão central deste artigo.

As mulheres que compõem os grupos entrevistados foram acionadas a partir de indicações de conhecidos meus de diferentes redes de contato. Elas não se conhecem entre si. A seleção das entrevistadas se deu a partir da faixa etária, grau de escolaridade (ensino superior) e orientação sexual.

\section{Velhice, histórias de amor e homossexualidade feminina}

Difunde-se a ideia de que os corpos envelhecidos não têm espaço no mercado erótico e essa desvantagem acaba por afastar as pessoas mais velhas do exercício da conquista sexual. Essa imagem é ainda mais forte quando tratamos de mulheres. Na medida em que envelhecem, as mulheres são vistas e se veem como pouco atrativas sexualmente. As marcas corporais do envelhecimento como rugas e cabelos brancos são desvalorizadas do ponto de vista estético e comprometem o potencial de sedução daquele corpo (Goldenberg, 2008). Afirma-se também que no Brasil essa desvalorização estética do corpo velho é bastante disseminada, refletindo-se no elevado número de pessoas que realizam (ou que gostariam de realizar) diversos procedimentos, inclusive cirúrgicos, que prometem o rejuvenescimento físico. Diante desse clima de negação da velhice, é comum ouvirmos as mulheres mais velhas reclamarem 
da invisibilidade de seus corpos e da consequente perda do poder de atração sexual.

Essas afirmações podem ser todas matizadas. Nem sempre esse sentimento de invisibilidade é compartilhado por todas as mulheres mais velhas em todas as situações. Existem padrões estéticos distintos na sociedade e nem sempre o que parece ser símbolo de envelhecimento num contexto tem o mesmo significado em outro. O que é sexualmente atrativo também é algo muito variável. Entre as mulheres que entrevistei para essa pesquisa, a idade não foi referida como um obstáculo em suas vidas amorosas. Ao contrário do que se esperaria encontrar no discurso de mulheres com mais de 60 anos de idade, as entrevistadas continuam namorando e coabitando com suas parceiras e não se referem à velhice como um elemento que dificulte seus encontros amorosos com outras mulheres.

As parceiras das mulheres idosas entrevistadas são, em média, dez a 15 anos mais jovens do que elas; invertendo um movimento que as entrevistadas experimentaram anteriormente em suas vidas: quando elas eram mais jovens e iniciavam sua vida sexual, as primeiras parceiras eram mais velhas do que elas. Agora são elas que encontram mulheres mais jovens para se relacionarem e, em algumas situações, mulheres provenientes de meios sociais mais modestos, com pouca escolaridade e nível de renda mais baixo.

O novo caminho citado para o encontro de prováveis parceiras sexuais é a internet. As salas de bate-papo nos sites GLS² são acionadas com fins de sociabilidade e de paquera. Segundo Heilborn (2009, p. 83):

Com a net, o encontro entre pessoas de mundos sociais distantes é facilitado e, nesse sentido, ganha força um padrão quase desconhecido anteriormente para o mundo lésbico de camadas médias no Rio de Janeiro: o contato entre sujeitos de origens sociais muito distintas, modelo fortemente documentado para o mundo gay masculino.

Esse novo circuito vem se somar aos tradicionais meios de interação: fã-clubes de cantoras, como Zélia Duncan, Ana Carolina, Cássia Eller e também cantoras mais antigas, como Maysa, ${ }^{3}$ por exemplo. No Rio de Janeiro, as

2 Sigla que se refere à espaços de sociabilidade que reúnem gays e lésbicas.

3 Cantoras brasileiras de sucesso, conhecidas também por reunirem lésbicas entre seus fãs.

Horizontes Antropológicos, Porto Alegre, ano 16, n. 34, p. 213-233, jul./dez. 2010 
mulheres entrevistadas lembravam com saudades do Bar Gaivota, ${ }^{4}$ um recanto que nos anos 1980 foi muito frequentado por elas e palco de encontros amorosos. Hoje elas se ressentem da ausência desses espaços. Os lugares públicos de sociabilidade que agregam homossexuais são vistos por elas como mais voltados para o público jovem, onde elas não se sentem bem: o tipo de música que é tocada não agrada, a frequência é considerada jovem demais (em torno de 20/30 anos de idade) e os horários de funcionamento são vistos como impeditivos. Assim, as atividades de sociabilidade dessas mulheres são fortemente marcadas pela frequência às casas umas das outras e pela configuração de uma rede de amizades feita de trocas sentimentais, materiais e sexuais.

A vida sexual do par lésbico foi tratada na literatura sobre o tema como subsumida a outros mandamentos de configuração do casal. Segundo essa bibliografia, o casal de mulheres constitui-se por um forte sentimento de conjugalidade aliado a uma noção distintiva das individualidades. Os membros da díade partilham projetos e dividem as tarefas e obrigações comuns, sem diluírem suas individualidades. A prática sexual é ocultada como elemento determinante da união daquele casal. A tese de doutorado de Maria Luiza Heilborn, publicada em 2004, apresenta essas conclusões a partir de estudo centrado em mulheres de camadas médias, realizado no início dos anos 1990 e com pessoas da faixa etária entre 35 e 45 anos de idade. ${ }^{5}$ Os segmentos médios entrevistados por mim estão em outro momento do ciclo da vida (entre 60 e 73 anos de idade), já viveram algumas relações duradouras, com experiências de coabitação e, no momento da entrevista, estavam se relacionando com mulheres mais jovens do que elas. Em seus depoimentos, a prática sexual é vista como elemento fundamental para a existência do casal lésbico. Se o sexo não é o motivo da união e sim o amor e a amizade, a manutenção do vínculo depende da alimentação tanto da estima quanto da atração sexual.

O sexo pra mim é muito importante, eu não consigo ficar sem sexo mais de uma semana e sempre foi assim e continua assim. No dia a dia da relação a atração física pesa muito. Eu diria que é $70 \%$ sexo e $30 \%$ o resto. (Roberta, 60 anos).

\footnotetext{
4 As entrevistadas relataram que esse bar localizava-se na Barra da Tijuca, região da cidade que na década de 1980 ainda não era tão populosa quanto é hoje. O bar contava com música ao vivo e foi indicado por elas como um "território livre” para o público gay, inclusive para as lésbicas.

5 No roteiro da pesquisa de Heilborn (2004) não havia perguntas sobre prática sexual. Isso também contribui para a ausência do tema nos relatos dos entrevistados.
} 
No entanto, quando perguntadas o que exatamente elas faziam para alimentar a atração sexual entre o casal, as respostas eram muito vagas. Em comparação, mulheres lésbicas mais jovens (entre 35 e 45 anos de idade), entrevistadas em outro segmento dessa pesquisa, foram bem mais explícitas na nomeação de recursos eróticos para o casal, como a compra de produtos em sex shops. As mais jovens também assumem um repertório sexual mais variado, enfatizando a existência de uma transitoriedade nas maneiras como cada uma se posiciona durante o ato sexual. Portanto, se as idosas afirmam a importância da manutenção do sexo como elemento que configura o casal lésbico, são as mais jovens que nomeiam mais diretamente as formas e recursos utilizados para "quebrar a rotina" da vida sexual do par.

Outro ponto que merece destaque quando nos perguntamos sobre a relação entre velhice e homossexualidade feminina está na maneira como as mulheres idosas produzem uma história afetiva-sexual de suas vidas. Essa história é um material precioso na medida em que descortina as relações entre os sujeitos e os contextos sociais, as redes de contato social que possibilitaram no passado (e ainda possibilitam) às mulheres entrevistadas ter a experiência da homossexualidade feminina na cidade do Rio de Janeiro. No momento da vida em que elas se encontram, a oportunidade de contar sua história de vida sexual - uma história que permaneceu na sombra por alguns anos - é vista como uma forma de dar sentido à essa trajetória e de colocar-se como sujeito dessa história.

$\mathrm{O}$ ato de narrar sua história, suas vivências ao longo do tempo, permite à entrevistada construir uma apresentação de si, uma biografia no sentido que Bourdieu (1996) empresta ao termo. Os eventos e atores deslocados para o centro da cena ou para suas margens pontuam as relações que a narradora entende como significativas. Segundo Plummer (1995), ao registrarmos "histórias sexuais" é necessário termos em mente o contexto no qual elas se produzem e com o qual elas se relacionam. No caso dessa pesquisa, faz parte do contexto da narração a interação entre uma entrevistadora mais jovem, heterossexual, e uma narradora pelo menos 20 anos mais velha e homossexual. As histórias contadas supõem como ouvinte alguém que não compartilha dos mesmos códigos. Além disso, são depoimentos que se dirigem para alguém cuja distância etária não permite o compartilhamento de referências temporais. A cidade era outra e eram outras também as formas de circulação nos pontos marcados como espaços abertos às práticas e interações entre homossexuais. Considerando que estamos nos referindo à homossexualidade feminina, cujos

Horizontes Antropológicos, Porto Alegre, ano 16, n. 34, p. 213-233, jul./dez. 2010 
espaços sempre foram mais restritos do que os masculinos, podemos compreender o quanto essas narrativas muitas vezes nos falam da quase ausência de lugares. Uma metáfora perfeita para a invisibilidade da homossexualidade feminina. Não obstante, a homossexualidade foi vivida por elas, espaços foram construídos para essa experiência e são hoje material para a narrativa.

As memórias postas em jogo nesses relatos são construções individuais baseadas em referências contextuais. Como toda memória, articula-se com o porvir na medida em que o que é acionado sobre o passado está em conexão com o presente e com os projetos futuros dessas narradoras.

O passado, assim, é descontínuo. A consistência e o significado desse passado e da memória articulam-se à elaboração de projetos que dão sentido e estabelecem continuidade entre esses diferentes momentos e situações. (Velho, 1994, p. 103).

A memória coloca em movimento a trajetória individual dessas mulheres, confere um espaço para que elas se apropriem de lugares que estavam "quase esquecidos", de momentos que se tornam significativos no presente. São momentos significativos porque constroem uma percepção do que as constitui enquanto sujeitos com uma vida afetivo-sexual, com histórias de amor que podem ser contadas no presente e que dão sentido ao curso da vida. A velhice é vista como uma oportunidade aberta para rememorar e construir os fios dessa história. A velhice é, simultaneamente, o tempo em que essa história se mantém e se conecta com projetos futuros; é, portanto, um momento de criação (Lins de Barros, 1998).

\section{Memórias da lesbianidade: a primeira vez}

Eu devia ter uns 20 anos, 19 anos, por aí. Foi por correspondência, na época não existia sala de bate-papo, nem computador. Você bota isso há 40 anos atrás. A gente costumava ler muita revista, tinha aquele cantinho dos leitores onde um se correspondia com o outro. Aí um dia eu estava malzona mesmo, e eu coloquei um anúncio dizendo que queria me corresponder com fãs da Maysa. Eu adorava a Maysa. ${ }^{6}$ Aí eu recebi muitas cartas. Só que quando eu recebi as cartas, eu já

6 Maysa é uma consagrada cantora brasileira. Morta em 1977 num acidente de automóvel, fez grande sucesso nos anos 1960, e sua trajetória é vista como a de uma mulher transgressora para seu tempo, pois abandonou um casamento para abraçar a carreira artística (Lira Netto, 2007).

Horizontes Antropológicos, Porto Alegre, ano 16, n. 34, p. 213-233, jul./dez. 2010 
estava outra, já estava bem e aquilo já não era eu quando escrevi. Aí eu achei muito engraçado aquilo tudo e fui jogando as cartas fora. Mas uma delas me chamou a atenção, aí eu resolvi separar e responder. Aí respondi, aí a menina depois me respondeu de volta e a gente começou a trocar correspondência. Até que um dia, até então eu nunca tinha tido ninguém, eu achei que estava gostando dela de uma maneira diferente. Aí começamos a nos corresponder. Até que um belo dia, eu mandei uma carta pra ela, dizendo que eu não mandaria mais porque eu estava tendo um sentimento diferente, estava gostando dela. Tinha uma música que me lembrava muito dela e tal, e que eu não ia mandar mais. E numa coincidência, no mesmo dia ela me mandou uma carta, falando as mesmas coisas. Parece coisa de cinema. Mas aí a gente começou a, a gente sentiu que estava se gostando, as cartas foram ficando mais frequentes. Só que até então, a gente não falava nada, como era fisicamente, nada... Até que um dia a gente começou a trocar telefones e ela veio pro Rio... Não, eu fui a São Paulo, fui conhecê-la. Aí foi um choque, porque ela era dez anos mais velha que eu. Eu tinha 20 e ela, 30. Só que ela tinha a cabeça quase toda branca e eu parecia um menino. Então, o primeiro impacto foi aquele choque, mas a gente já se gostava, e aquilo ali foi o de menos. Aí, passaram uns três meses, eu saí de casa, aluguei um apartamento. Aí a gente foi morar junto. (Roberta, 60 anos).

Manter relações sexuais e assumir uma identidade sexual são processos que não se associam como etapas sequenciais de um curso de vida organizado. Ouvir as narrativas sobre os primeiros encontros sexuais é uma oportunidade para entendermos quais são os elementos acionados pela narradora para "fazer sentido" e assim termos um material que pode revelar

o jogo entre os significados sociais e as interações sociais relevantes para a representação da própria subjetividade de quem conta - e se levarmos em consideração que toda narrativa também é construída por quem ouve, a sua análise pode nos proporcionar elementos importantes para compreender o papel da elaboração das experiências de uma coorte geracional no aprendizado e difusão de narrativas-mestras sobre a origem do desejo sexual. (Simões, 2004, p. 432).

Nas trajetórias das mulheres entrevistadas elas foram perguntadas sobre o início de suas vidas sexuais. As mulheres que têm relações sexuais com mulheres me perguntavam de volta: "Você quer saber de qual início? Com homem ou com mulher?" Eu respondia: "E quero saber o que você acha que é seu início." Essa era a deixa para que eu fosse apresentada a, pelo menos, dois 
começos de vida sexual e a uma temporalidade muitas vezes difícil de acompanhar. Essa separação dos roteiros, um "hetero" outro "homo", é um artifício para "fazer sentido" e, como todo artifício, deve ser interpretado como nos orienta Simões na citação acima: elemento importante para compreender "as experiências de uma coorte geracional no aprendizado e difusão de narrativasmestras sobre a origem do desejo sexual".

Todas as mulheres se iniciaram sexualmente com mulheres mais velhas do que elas, com uma distância etária bastante significativa: entre dez 15 anos de diferença. A única exceção se dá no caso da mulher que teve sua primeira relação homossexual aos 57 anos. A parceira, nesse caso, é que era mais jovem, tinha 45. Mas tinha mais experiência, pois já tinha tido várias relações afetivas e sexuais com mulheres. Essa grande diferença de idade para a primeira relação não se verifica nos relatos de lésbicas mais jovens. Nesse caso, as primeiras parceiras sexuais são encontradas em cenários como a escola e a universidade, onde pessoas de faixa etária próxima tendem a estar. No caso das mais velhas, os contextos de encontro são outros; as primeiras relações se deram com mulheres conhecidas em ambientes de sociabilidade mais exclusivos, nos quais a homossexualidade não era recriminada. Duas mulheres conheceram suas parceiras através de fã-clubes de cantoras de sucesso no Brasil, outra conheceu sua primeira parceira num bar gay no final dos anos 1970. Acredito que essa diferença nos cenários influi na redução da distância etária entre as parcerias sexuais na primeira relação. Os contextos de encontro homoerótico são hoje mais plurais do que eram no passado.

Nos relatos dessas mulheres sobre a primeira transa com mulher há uma ênfase na dimensão do afeto em detrimento do prazer erótico. A aproximação com a parceira sexual é paulatina, começando como uma relação de amizade e cumplicidade que, num determinado momento, incorpora o intercurso sexual em seu repertório. São relações que têm certa durabilidade e são relatadas como sendo o "primeiro grande amor". A linguagem dos sentimentos se faz muito presente nessas narrativas e coloca o sexo como o corolário de uma trajetória, acima de tudo, sentimental. O laço de afeto prescinde de justificativas e, uma vez estabelecido, abre caminho para a possibilidade de um outro processo: o da construção de si como homossexual.

Para as mulheres que se apresentam como homossexuais, a primeira relação é lida por elas como uma descoberta de algo que estava lá desde sempre. A primeira transa é um portal que leva a um universo de sentidos que são, ao 
mesmo tempo, estranhos e familiares. A primeira vez com uma mulher aparece como um encontro espontâneo com o afeto. Nos relatos enfatiza-se a ideia de autenticidade e singularidade das relações. Apesar de existir algum grau de conflito interno e medo da descoberta e reação da família, todas apontam a primeira relação sexual com outra mulher como um momento de realização de si.

Aquelas que tiveram antes experiências heterossexuais, uma delas inclusive foi casada e teve dois filhos, fazem questão de estabelecer um corte entre o "sexo com homem" e o "amor com mulher". O prazer físico está presente nas relações sexuais com os homens, mas o sentimento de "completude" e de "realização" só se coloca nos relatos das experiências com mulheres.

Ah! Foi maravilhoso! [a primeira transa com uma mulher] Nossa! Eu já tinha me relacionado com homens e é uma diferença! Em tudo, absolutamente em tudo é diferente. Por que a diferença? Primeiro porque energeticamente rolou, quimicamente também foi muito melhor. O próprio ato em si é muito mais completo. Eu já tinha sido noiva, já tinha tido amantes. Eu tive tantos amantes quanto meu caderninho dava. Mas era uma coisa apenas física. A minha relação com homem sempre foi uma coisa física, eu tinha orgasmo com homem também, mas é outra história. (Alba, 60 anos).

\section{Fazendo-se lésbica: um contraste entre geracões}

Houve toda uma cultura de época, de mentalidade. Na época que eu comecei a assumir que era entendida, que comecei a frequentar boates e tudo, era uma distinção muito grande entre sapatão e as namoradas dos sapatões. Então, hoje você já não vê... Hoje você cruza com pessoas entendidas e você não identifica fisicamente. A postura, a maneira de vestir era totalmente diferente. Naquela época não. Você tinha que usar roupa pesada.

[Pergunta: "Naquela época que você diz..."]

Quarenta anos atrás. Pra você ver a mentalidade: minha mãe quando soube disse que preferia que eu ficasse com um homem desquitado. "Preferia que ela ficasse com um homem desquitado do que com uma mulher!" Por aí você vê a mentalidade da época. O homem desquitado era o terror. O homem casado ou desquitado, era um terror alguém ficar com eles. Então, você imagina a cultura, né? Então, naquela época, as pessoas tinham duas classes que tinham que ser distintas. Então até eu saber em que lado eu estava, eu tinha que assumir um lado. Então, eu fiquei do lado dos sapatões. E sempre tive aquela postura. Eu sempre fui muito moleque, muito menino de rua, de brigar, de... Sempre tive 
um comportamento mais masculinizado, até na convivência em criança, então aquilo era uma coisa natural pra mim. Não era nem forçado, eu fazia por... me vestia por gostar. Lógico que quando comecei a trabalhar tive que usar salto, não podia só usar calça comprida, era saia, meia fina, maquiagem. Mas também eu encarava numa boa, não era nenhum sacrifício maior. Mas quando podia tirar aquela fantasia toda, era ótimo. Então, tinha aquela cultura toda na época. Então, com o passar do tempo, foi evoluindo, as coisas foram mudando. Hoje quando eu saio com essa aí [atual namorada], ela fala: "Vai botar um batonzinho." Eu já tenho que botar, eu já boto, já não é tão forçado. Já me acostumo mais. Então, houve mudança também. [...] Começou a mudar também o meu comportamento na cama. Até então eu tinha relação, mas tinha aqueles preconceitos antigos. Eu jamais aceitei que alguém fizesse alguma coisa por fazer. Fez em mim, me deu prazer, então eu tenho que fazer também [...] Eu sempre assumi a postura de dar prazer. Hoje já não é mais assim, foi uma mudança de postura, de tudo.

A história de Roberta, 60 anos, contém alguns elementos importantes. Primeiro, a divisão que ela estabelece entre o passado, onde havia "preconceitos antigos" e uma marcação muito clara de fronteiras entre as próprias mulheres: os "sapatões" e "suas namoradas" e o presente, onde se faz vigente uma indistinção, um tempo onde todas são, segundo sua classificação, "entendidas". ${ }^{7}$ Em segundo lugar, ela faz coincidir seu caminho de identificações com essa temporalidade. No passado ela se viu levada a assumir "um lado", e ficou com o lado dos "sapatões"; hoje ela passou a se ver como "mulher". Um tempo não é necessariamente melhor do que o outro. Roberta não se sentia violentada ao vestir "roupa pesada" ou a ter uma vida sexual onde ela era a encarregada de "dar prazer" à parceira; a mudança trouxe um novo hábito à sua vida sexual e à sua apresentação de si. As próprias parceiras com quem ela vem a se relacionar atualmente são mulheres que pedem a ela que "use um batonzinho". Essa estruturação que Roberta faz de sua vida sexual

\footnotetext{
Carmen Dora Guimarães (2004), em seu trabalho O homossexual visto por entendidos, faz uma análise da categoria "entendido". O estudo aborda a homossexualidade masculina na zona sul carioca dos anos 1970. A categoria nativa "entendido" é usada nesse contexto para distinguir um tipo específico de homossexual masculino, diferente da "bicha". A "bicha" ostenta trejeitos e trajes mais femininos, ao passo que o entendido não compartilha dessa mesma performance de gênero. Essa diferenciação reflete uma hierarquização do mundo gay masculino. No caso da entrevistada, o termo "entendida" é usado como um termo amplo, sinônimo de lésbica, independentemente de sua performance de gênero.
}

Horizontes Antropológicos, Porto Alegre, ano 16, n. 34, p. 213-233, jul./dez. 2010 
é um exemplo da forma como as trajetórias tentam fazer sentido para si e para os outros. Roberta localiza a história de sua vida sexual num contexto marcado por uma transformação da visibilidade das relações homossexuais. O passado ao qual ela se refere, "40 anos atrás", é visto como um tempo em que se devia escolher um lado para ser homossexual, um lado que mimetizava o masculino, tanto externamente, na aparência, quanto na postura sexual. O presente é um tempo em que a imagem feminina é resgatada e as relações sexuais ganham um estatuto de terreno de trocas entre as parceiras, onde a regra é fazer o que se sente.

Alba, 60 anos de idade, fala da atual companheira, dez anos mais jovem do que ela, e que nunca havia tido relações sexuais com mulher. Elas se consideram casadas, embora não vivam na mesma casa por "motivos operacionais": Alba tem três filhos e a companheira também, "fica difícil juntar seis jovens numa mesma casa". Alba me conta sobre o processo de iniciação sexual da parceira:

Eu disse a ela: "É só você ter uma relação direta com onde você tem prazer. Você descobre em você, vai ser igualzinho em mim porque nosso corpo é igual."

Essa igualdade de identificação corporal é a chave do prazer. Essa mesma entrevistada relatou que sentia uma enorme "compaixão" pelos transgêneros e travestis porque eles "não conseguem se ver nos corpos que têm". O corpo reconhecido como o mesmo vira a base da experiência sexual.

Em depoimentos de mulheres lésbicas mais jovens, também pertencentes às camadas médias urbanas cariocas - entrevistadas em outro segmento dessa pesquisa - o discurso tem outro tom. É importante resgatá-los para que tenhamos uma noção mais precisa das diferenças que marcam o olhar das lésbicas mais velhas sobre seus percursos de vida. Nesse sentido, a experiência das jovens é tratada aqui como um contraste em relação à experiência das mais velhas.

Joana, 41 anos, apaixonou-se por uma colega de escola aos 17 anos de idade. Segundo ela, foi uma época maravilhosa, pois ela e a namorada pertenciam a um grupo de amigos, "todos gays e muito criativos, rebeldes, malucos, artistas". Era para ela um "universo particular" onde ninguém precisava se definir: "a gente se sabia gay, não era preciso dizer o nome". Algumas dessas pessoas ainda pertencem ao círculo de amizades de Joana, alguns são gays até 
hoje, como ela, e outros não, "estão casados [com alguém do sexo oposto] e com filhos", como ela diz. Joana, nessa mesma época de adolescente, viveu simultaneamente uma paixão por um rapaz e pela namorada. Quando Joana entrou para a faculdade é que passou a se relacionar exclusivamente com mulheres, suas relações foram muito intensas e dramáticas, com cenas de ciúme e relações com mulheres que queriam que ela fosse "o cara da relação". Nesse período, Joana teve uma vida profissionalmente instável, parou e retomou os estudos diversas vezes, dependeu do dinheiro dos pais para viver e viciouse em cocaína. O fim desse período "mais barra-pesada", como ela o define, coincidiu com o encontro com a atual companheira com quem vive há 13 anos, alguém que a ajudou a crescer e a se libertar.

Diferente de hoje, das meninas e dos meninos homossexuais que começam a experimentar, você tem mais informação e eu não tinha. Então, na verdade, você traz pra tua relação muito de uma ideia de sexualidade heterossexual, do papel de cada um, do que cada um faz. Eu acho que eu demorei um tempo pra tirar isso um pouco da minha cabeça e acho que foi o tempo de maturidade mesmo, de estar maduro e dizer assim: "Eu gosto disso." Significa eu gosto, não é porque é ativo ou passivo, isso era muito presente, eu vivi isso, a gente viveu muito isso nessa época, alguém tinha que assumir alguns papéis. Eu acho que o marcador de mudança está aí: cada um faz o que bem entender, você não tem que ter papéis definidos. Eu vi muito isso pela R. [a parceira anterior], eu tinha que ser muito ativa, porque ela tinha um perfil muito passivo, das mulheres que vinham de relações com homens, e ela não gostava de mulher. Ela foi fundamental pra mim, pra saber o que eu não era. A O. [atual parceira],[silêncio, fica pensativa alguns momentos] eu não consigo ainda explicar isso, eu não saberia explicar. A R. foi fundamental, não é a relação que eu quero. Eu quero uma relação em que eu posso ser o que eu bem entender, o que eu quiser. Com a O. é exatamente isso. Foi uma descoberta, e a gente pôde ser tudo. Mas sempre com alguma coisa, que eu não entendia o que era. Hoje eu vejo, não era nada, é natural, você está livre, você está liberto, isso não quer dizer que é passivo ou ativo, isso não. Pode ser que uma goste mais de uma coisa, e a outra não, mas não é pré-demarcado, acontece. Mas a R. me marcou porque ela trouxe uma história muito forte heterossexual e me chamava pra um papel muito de... chamava ou eu me fazia, sei lá, e não ficou legal. Com a $\mathrm{O}$. a gente pode, a gente vive tudo, a gente brinca com isso. A gente fala: "Você está preguiçosa hoje, hein?", aí uma fica mais... e isso é muito bom, a gente falar das nossas vontades. Enfim, ninguém está forçando ninguém a ser nada. Não existem papéis definidos.

Horizontes Antropológicos, Porto Alegre, ano 16, n. 34, p. 213-233, jul./dez. 2010 
Joana enquadra nas suas relações com mulheres o seu processo de aprendizagem sobre a vida sexual. A maturidade e o amor de uma mulher específica são os responsáveis por uma mudança que ela considera que foi para melhor, o sair de uma posição fixa e masculinizada para uma relação de troca simétrica e aprendizado mútuo. Essa mudança sexual coincide com uma saída da vida desregrada e sofrida que estava levando. Joana constrói uma leitura mais psicológica da mudança e se coloca num lugar de escolha. Não é por acaso que todo o processo de mudança foi acompanhado por sessões de psicanálise lacaniana.

As gerações têm uma destacada influência sobre a percepção do fluxo das identificações e práticas sexuais. No caso das mulheres mais velhas parece haver um processo marcado fortemente pelo dualismo e por uma visão de "naturalidade" das relações sexuais. O dualismo se expressa no discurso de que as mulheres tinham que fazer uma opção, como se houvesse uma pressão social para assumir um lugar e um papel no universo da homossexualidade feminina: ser o sapatão ou a namorada do sapatão. Esse tempo do dualismo é contraposto a um tempo presente onde as fronteiras desapareceram, onde já não se identifica mais tão facilmente quem é e quem não é "entendida". Nesse quadro atual, a única coisa que pode guiar a prática sexual é o "espontâneo". Roberta só deixa alguém lhe "dar prazer" se ela "sentir" que aquela pessoa "realmente quer isso". Alba também fala de uma suposta naturalidade onde as mulheres coincidem sexualmente porque seus corpos são iguais. Na geração mais jovem, o discurso marca uma fuga aparentemente mais consciente dos mecanismos que geram fixidez, um processo reflexivo mais marcado pela ideia de busca de si, de autoaprimoramento.

Esse processo reflexivo e de aprimoramento se dá quando as mulheres conseguem dialogar entre si, a conversa é um elemento muito valorizado por essa geração mais jovem de lésbicas. No depoimento de Joana, esse aprendizado do diálogo denota a conquista de autonomia pessoal no campo afetivo e pessoal, o que ela chama de "maturidade". Um aprendizado que culmina na experimentação de uma sexualidade sem papéis. Essa entrada da ideia de autodeterminação na construção da trajetória homossexual é decorrente de uma mudança no contexto social de vivência das relações sexuais em geral e das relações entre pessoas do mesmo sexo. As mais jovens produzem um conjunto de significados sobre a sexualidade em que esta é vista como uma prática relacional que supõe uma vigilância individual sobre seus próprios

Horizontes Antropológicos, Porto Alegre, ano 16, n. 34, p. 213-233, jul./dez. 2010 
atos e escolhas. As mulheres não só refletem sobre sua trajetória sexual (como fazem também as mulheres mais velhas), mas acreditam no seu aperfeiçoamento através do acúmulo de relações ao longo da trajetória de vida.

Entendo que essa crença no aperfeiçoamento não é exclusiva das homossexuais, mas foram elas, particularmente as mais jovens, que falaram explicitamente sobre a melhoria da interação sexual como uma prática em suas vidas, citando inclusive recursos a produtos eróticos como um elemento desse aperfeiçoamento. Essa geração mais jovem tem vivido as relações homoeróticas num ambiente onde as oportunidades de encontro, ainda que vigiadas e discriminadas no universo social mais amplo, encontram nichos sociais onde podem se expressar de alguma forma (como os grupos de amigos, espaços de sociabilidade). É também essa a geração que viu emergir os primeiros sinais dos movimentos políticos gay e lésbico dentro e fora do Brasil, e tem sido alvo da abertura de um mercado de consumo e entretenimento, principalmente entre as camadas médias urbanas, o que dá legitimidade à apresentação pública da homossexualidade, ainda que ela também venha eivada de estereótipos "politicamente corretos": como o do gay viril ou da lésbica feminina.

As gerações futuras talvez tenham uma outra concepção sobre sua própria trajetória sexual, pois estão relacionando-se afetivamente e sexualmente num universo em que a experiência da sexualidade vem sendo destacada e confundida com aquilo que Eugenio (2006) sublinhou como uma certa experiência de consumo hedonista, particularmente marcante entre determinados segmentos de jovens dos estratos médios. A homossexualidade feminina nas gerações mais jovens hoje tem sido vivida e narrada num contexto onde, por um lado, parece haver maior tolerância, existem mais espaços disponíveis para encontro de parceiras hoje do que havia para as gerações anteriores. Por outro lado, essa "visibilidade" vem acompanhada por uma profusão de discursos explicativos sobre si. Não basta gostar de outras mulheres, mas há todo um vocabulário geracional explicativo desse desejo, um vocabulário que afirma essa posição diante das demais e que assim a diferencia de outras posições: heterossexual, bissexual, ao mesmo tempo em que fomenta condições para ambiguidades. É todo um universo de classificações que se impõe ao olhar reflexivo dos sujeitos. Essas classificações são produzidas contemporaneamente e afirmam várias possibilidades de "ser lésbica".

Em pesquisa sobre as trajetórias de lésbicas feministas norte-americanas da geração baby boom, ou seja, nascidas após a Segunda Guerra Mundial, 
Arlene Stein (1997, p. 200) reflete sobre os caminhos abertos às novas gerações:

Many younger women coming of age and coming out today are also reconstituting lesbian identity, in ways that tolerate inconsistency and ambiguity. They simultaneously locate themselves inside and outside the dominant culture as they pursue a wide range of projects. Their strategic deployment of lesbian/gay identities is balanced against their recognition of the limits of such identities.

\section{Consideracõoes finais}

Um aspecto que chama a atenção se contrastamos essas diferentes posições etárias, as mulheres com mais de 60 anos e as mulheres com idades em torno dos 40 anos, é a transição sutil que começa a se operar no discurso delas a respeito das possibilidades de exercício da lesbianidade. No depoimento de Roberta, 60 anos, a transição de uma sexualidade mais marcada pela ideia de papéis definidos para uma sexualidade mais "espontânea" é lembrada como uma passagem que marca a evolução dos tempos, a superação de preconceitos sociais mais amplos que possibilitam uma vivência diferente da homossexualidade feminina hoje. Entre as demais entrevistadas mais velhas, a referência às mudanças nas relações homossexuais é marcada pela lembrança que elas têm do quanto era difícil reconhecer a própria homossexualidade na juventude, pois lhes faltavam meios para isso. Era algo sobre o qual não se pensava, não se falava. O processo de constituição de uma trajetória homossexual foi longo e implicou o estabelecimento de uma rede fechada de amigas que garantiu espaço para o exercício da homossexualidade e um afastamento da família de origem. $\mathrm{Na}$ opinião delas, as mulheres mais jovens hoje têm muito mais oportunidades do que elas tiveram.

Entre as entrevistadas de 40 anos, que também acham que as jovens de hoje são privilegiadas em termos de aceitação social da homossexualidade feminina, o processo de constituição de uma trajetória homossexual foi menos marcado pela constituição de uma rede exclusiva de amigas. Suas relações atravessam, muitas vezes, redes de amizade mistas e a experimentação sexual é vivida como um processo sobre o qual se desenvolve um olhar atento, voltado para a busca de aprimoramento das relações sexuais. O dualismo "ser sapatão" ou "ser namorada de sapatão" marca a referência a um contexto 
antigo. Esse dualismo parece ter começado a ser questionado no momento em que as entrevistadas de 40 anos começavam suas trajetórias sexuais. Creio que o impacto do discurso feminista no Brasil de final dos anos 1970 e início dos anos 1980 foi importante para possibilitar às mulheres um maior relaxamento dessas fronteiras muito rígidas em relação ao comportamento sexual, inclusive entre as lésbicas. A superação de uma rigidez entre ser sapatão de um lado ou ser feminina de outro pode ser uma das novidades nessa paisagem dos costumes dos anos 1970/1980. No entanto, é mais uma vez importante lembrar, essa novidade não se espraia igualmente por todos os segmentos sociais.

Outro ponto que merece destaque é o valor atribuído à maturidade. Em ambas as faixas etárias entrevistadas, difunde-se a ideia de que o acúmulo de experiências afetivas e sexuais ao longo da vida é importante para o processo de afirmação de si. O significado dessa afirmação muda de tom de acordo com a geração. Entre as mais idosas, a afirmação de si é produzida no momento em que elas podem olhar para trás e dar conta dos obstáculos que foram ultrapassados para que hoje, aos 60 anos, tenham uma vida independente e autônoma. Vida essa que inclui um retorno às relações familiares. Algumas se ocupam de cuidados com os pais, agora muito idosos e doentes, e que por tanto tempo se afastaram delas. No caso das mulheres com 40 anos de idade, a maturidade é vista como uma conquista recente ou que está ainda em vias de ser conquistada. A maturidade é definida como uma oportunidade de refletir sobre suas escolhas, inclusive sexuais, e se confunde com o processo de busca de melhorias na qualidade das relações. Em ambas as gerações, há uma valorização das parcerias estáveis e duradouras e uma condenação (feita às gerações mais jovens) das interações sexuais momentâneas e fugazes.

Nesse sentido, essas mulheres se aproximam das mulheres heterossexuais de suas gerações, que também valorizam a maturidade como sinônimo de experiência de vida (Alves, 2004). Embora, como já afirmado no início do artigo, também se refiram de forma negativa ao passar dos anos porque eles representam um declínio do poder de atração sexual da mulher no mercado erótico heterossexual. Essa desvalorização sexual não apareceu no discurso das mulheres homossexuais entrevistadas nessa pesquisa.

Simões (2004) argumenta que a imagem do "coroa", homossexual masculino de mais idade, também não deve ser necessariamente vista de forma negativa. A velhice entre homossexuais masculinos adquire tons diferenciados 
de acordo com as trajetórias individuais que determinadas coortes etárias constroem. Os homossexuais masculinos que hoje chegam à meia-idade têm trajetórias diferenciadas das gerações anteriores e isso tem direta influência sobre a maneira como irão vivenciar a velhice.

Esta é a coorte que dispôs de um leque de escolhas mais amplo no campo das experiências sensoriais, das drogas não alcoólicas ao relaxamento das atitudes em relação ao sexo. É a que promoveu o reconhecimento explícito da homossexualidade como estilo de vida legítimo, fundou o movimento pelos direitos dos homossexuais, transformou a resistência à polícia no bar Stonewall num símbolo poderoso, data de referência de grandes demonstrações públicas do "orgulho gay". É também, por ironia trágica, a coorte que mais sofreu os efeitos devastadores da epidemia HIV-Aids. Ela começará a chegar ao período mais avançado da vida com sua peculiar história de percursos e enfrentamentos, que poderão conduzir a novas concepções sobre envelhecimento e homossexualidade. (Simões, 2004, p. 434).

O estabelecimento da relação entre velhice e homossexualidade não significa buscar se há algo de específico no envelhecimento de homossexuais. A etapa mais avançada do curso da vida não adquire marcas únicas porque os velhos em questão são gays ou lésbicas. São as trajetórias de vida, marcadas pelas vivências comuns de determinadas coortes etárias, que podem emprestar ao envelhecimento marcas distintivas.

\section{Referências}

ALMEIDA, G. E. Da invisibilidade à vulnerabilidade: percursos do "corpo lésbico" na cena brasileira face à possibilidade de infecção por DST e Aids. Tese (Doutorado em Saúde Coletiva)-IMS, Universidade do Estado do Rio de Janeiro, Rio de Janeiro, 2005.

ALVES, A. M. A dama e o cavalheiro: um estudo antropológico sobre envelhecimento, gênero e sociabilidade. Rio de Janeiro: FGV, 2004.

BOURDIEU, P. Razões práticas: uma teoria da ação social. Campinas: Papirus, 1996. 
EUGENIO, Fernanda. Corpos voláteis: estética, amor e amizade no universo gay. In: MENDES DE ALMEIDA, M. I.; EUGENIO, F. (Org.). Culturas jovens: novos mapas do afeto. Rio de Janeiro: Jorge Zahar, 2006. p. 158-176.

FACCHINI, R. Entre umas e outras: mulheres, (homo)sexualidades e diferenças na cidade de São Paulo. Tese (Doutorado em Ciências Sociais)Instituto de Filosofia e Ciências Humanas, Universidade Estadual de Campinas, Campinas, 2008.

GAGNON, J. An interpretation of desire. Chicago: Chicago University Press, 2004.

GOLDENBERG, M. Coroas: corpo, envelhecimento, casamento e infidelidade. Rio de Janeiro: Record, 2008.

GUIMARÃES, C. D. O homossexual visto por entendidos. Rio de Janeiro: Garamond, 2004.

HEILBORN, M. L. Ser ou estar homossexual: dilemas da construção da identidade social. In: PARKER, R.; BARBOSA, R. Sexualidades brasileiras. Rio de Janeiro: Relume-Dumará, 1996. p. 136-145.

HEILBORN, M. L. Dois é par: gênero e identidade sexual em contexto igualitário. Rio de Janeiro: Garamond, 2004.

HEILBORN, M. L. Homossexualidade feminina em camadas médias no Rio de Janeiro sob a ótica das gerações. In: VELHO, G.; DUARTE, L. F. D. Gerações, família e sexualidade. Rio de Janeiro: 7 Letras, 2009. p. 77-88.

LACOMBE, A. "Para hombre ya estoy yo": masculinidades y socializacion lésbica en un bar del centro de Río de Janeiro. Buenos Aires: Antropofagia, 2006.

LINS DE BARROS, M. M. Testemunho de vida: um estudo antropológico de mulheres na velhice. In: LINS DE BARROS, M. M. (Org.). Velhice ou terceira idade?: estudos antropológicos sobre identidade, memória e política. Rio de Janeiro: Fundação Getúlio Vargas, 1998. p. 113-168. 
LIRA NETTO. Maysa: só numa multidão de amores. Rio de Janeiro: Globo, 2007.

MUNIZ, J. Mulher com mulher dá jacaré: uma abordagem antropológica da homossexualidade feminina. Dissertação (Mestrado em Antropologia Social)-Museu Nacional/Universidade Federal do Rio de Janeiro, Rio de Janeiro, 1992.

PLUMMER, K. Telling sexual stories: power, change and social worlds. Nova York: Routledge, 1995.

SIMÕES, J. A. Homossexualidade masculina e curso da vida: pensando idades e identidades sexuais. In: PISCITELLI, A.; GREGORI, M. F.; CARRARA, S. Sexualidade e saberes: convenções e fronteiras. Rio de Janeiro: Garamond, 2004. p. 415-447.

SIQUEIRA, M. S. Arrasando horrores: uma etnografia das memórias, formas de sociabilidade e itinerários urbanos de travestis das antigas. Tese (Doutorado em Antropologia Social)-Centro de Filosofia e Ciências Humanas, Universidade Federal de Santa Catarina, Florianópolis, 2009.

STEIN, A. Sex and sensibility: stories of a lesbian generation. Los Angeles: University of California Press, 1997.

VELHO, G. Projeto e metamorfose: antropologia das sociedades complexas. Rio de Janeiro: Jorge Zahar, 1994. 